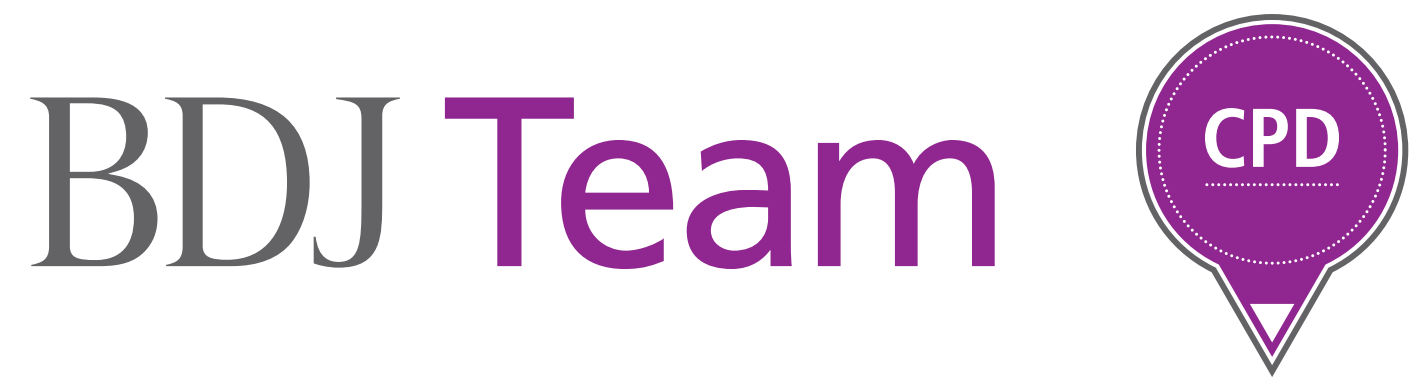

\title{
We want your views on BDJ Team CPD!
}

\section{Everybody knows that this October BDIA Dental Showcase rolls into the NEC in Birmingham from 22 - 24 October.}

What you won't know, is that the good folks here at BDJ Team are giving away an Apple Watch ${ }^{\text {TM }}$ (yes, giving away!) in exchange for your opinion. Interested? Read on...

At stand $\mathrm{G} 50$ we are running a survey to find out more about your CPD habits.

- Where do you do it?

- How much time do you spend on it?

- Do you do it on the move or when you have some spare time?

And the best bit is you will be entered into a prize draw to win an Apple Watch ${ }^{\mathrm{TM}}$.

If you subscribe to BDJ Team already, then you will know that once again in 2016 CPD is completely free - you just need to register your participation and then 10 more hours of verifiable CPD await you.

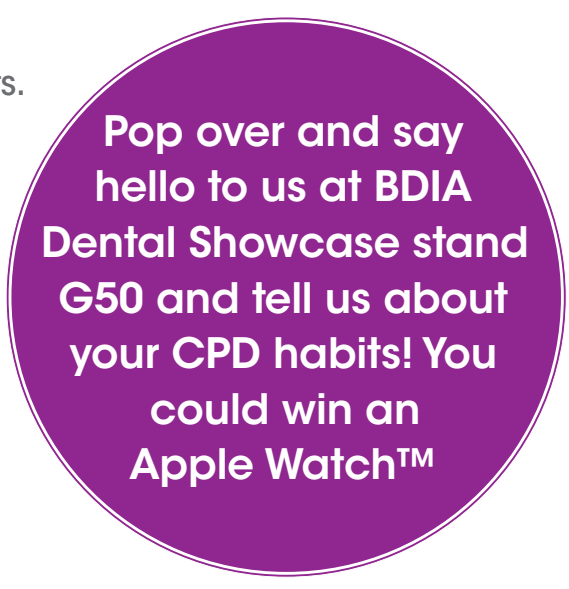

If you don't, then rest assured BDJ Team will provide you with a programme of verifiable CPD which will refresh and develop your knowledge from the convenience of your own practice or home.

If you are searching for core CPD, take a look at some of our recent and forthcoming articles:

- The role of saliva - September

- Recognition and treatment of anaphylaxis - June

- Patients with pacemakers - July

BDJ Team CPD will not only help you keep up-to-date in a broad spectrum of subject areas but it will also help to develop independent study skills and critical appraisal techniques in line with the GDC's aims and objectives.

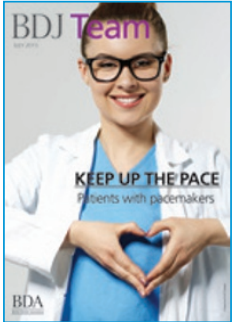

Pacemakers

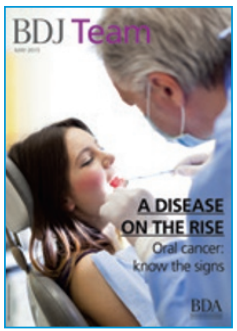

Oral cancer

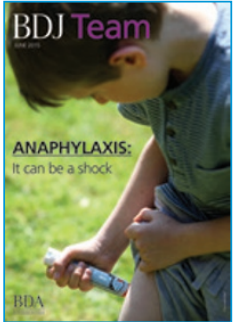

Anaphylaxis

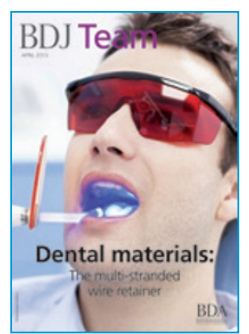

Dental materials 